\title{
The Ecology of the Tropical Compound Ascidian Trididemnum solidum. I. Reproductive Strategy and Larval Behaviour
}

\author{
F. C. van Duyl, R. P. M. Bak and J. Sybesma \\ Caribbean Marine Biological Institute (Carmabi), P.O. Box 2090, Curaçao, Netherlands Antilles
}

\begin{abstract}
Colonies in populations of Trididemnum solidum (Van Name) on the reefs of Curaçao release larvae throughout the year. The number of tadpoles released daily between 10.15 and $14.00 \mathrm{~h}$ ranged to ov'r 200 larvae colony $^{-1}$ and appears to be influenced by temperature and quantity of sunlight. The free-swimming period of the larvae is short, the majority settling within $15 \mathrm{mmn}$. Settlement was stimulated in the presence of attached larvae. Upon release, the larvae display positive phototaxis and a weaker negative geotaxis. At a later stage this is replaced by negative phototaxis. When offered a range of light intensities $\left(1250-1.3 \mathrm{u} \mathrm{Em}^{-2} \mathrm{~s}^{1}\right)$ most larvae preferred to settle at an intermediate but low radiation level. They showed a preference for natural coral rock as substratum over smooth or cleaned substrata and never settled on living coral surfaces. After settlement in the field, the larvae entered a 3 to 4 week period of external unactivity before growing out to small colonies. Mortality of recruits was very high. The observed characteristics of the reproductive strategy explain to a large extent the distribution of $T$. solidum on the reef
\end{abstract}

\section{INTRODUCTION}

One of the more conspicuous sessile organisms on the coral reefs in Curaçao - apart from the dominant stony corals (Scleractinia) - is a compound, encrusting ascidian. The small zooids are situated in whitish to purple coloured, 4 to $5 \mathrm{~mm}$ thick, colonies which grow as sheets to maximum sizes of over $1 \mathrm{~m}$ (Fig. 1). The tough tests of the colonies are heavily impregnated with stellate spicules. Identification of this organism was complicated by the existing confusion over the validity of the species Trididemnum savignii (Herdman, 1886) and T. solidum (Van Name, 1902). Examination of our material by Drs R. H. Millar (Scotland), F. Monniot (Paris) and T. O. Morgan (Puerto Rico) ascertained the animal to be Trididemnum, either the species savignii or solidum. We follow Millar (1962) and prefer the name $T$. solidum for specimens from the West Indies.

The role of Trididemnum solidum in the benthic reef system was obscure but potentially important, considering its abundance and the facts that the ascidians were found to contain abundant symbiotic algae and to overgrow the structurally important stony corals (Sybesma and Bak, 1979). The species is viviparous; the colonies frequently lodged mature tadpole larvae, visible on the colony surface, which were released daily through the test. Because reproduction strategies of reef organisms are poorly known our first effort in the investigation of the ecology of the ascidian was to study: the length of the reproductive period, time and number of larvae released per day, length of the freeswimming period, behaviour of free-swimming and settling larvae, growth and survival of recruits. Growth and survival of larger colonies of $T$, solidum, as well as aspects of its symbiosis with unicellular algae, are discussed by Bak et al., 1981 and Sybesma et al., 1981.

\section{MATERIAL AND METHODS}

\section{Reproductive Period}

Preliminary observations showed fully developed tadpole larvae to appear at the surface of the test 
during the day from $10.00 \mathrm{~h}$ to $11.30 \mathrm{~h}$ (Fig 1). Such larvae are subsequently released. These colonies, which displayed mature larvae at the colony surface, were termed reproductive colonies

We did in situ observations, using SCUBA gear, on the length of the reproductive period during $1 \mathrm{yr}$, from May 1978 to May 1979. Our observations fall into 2 categories; during May, June 1978 and April, May 1979 we made qualitative observations, checking weekly for presence/absence of reproductive colonies. The remainder of the year, 9 mo from July 4, 1978 to April 5, 1979, our study was quantitative. We counted the number of mature larvae prior to release present in colonies and the number of reproductive colonies of the Trididemnum population in two reef areas (Carmabi Reef Buoy 1, Vaersen Bay). Originally we

\section{Releasing Time and Number of Released Larvae}

Released tadpole larvae ascended vertically in the water column. This consistent behaviour permitted the use of traps, located over reproductive colonies, to catch the larvae released per time unit. We employed Plexiglas traps (modified after Alldredge and King, 1977), size $45 \times 40 \times 40 \mathrm{~cm}$. All emerging larvae moved up through a funnel into the closed upper part of the trap. Access to this closed compartment was through a slide door and the larvae were removed using a small slurp gun.

On 31 d (between October 5 and February 16) we collected all larvae hatched during the day from a single colony The larvae were subsequently counted in the laboratory. On $7 \mathrm{~d}$ we made counts of the larvae
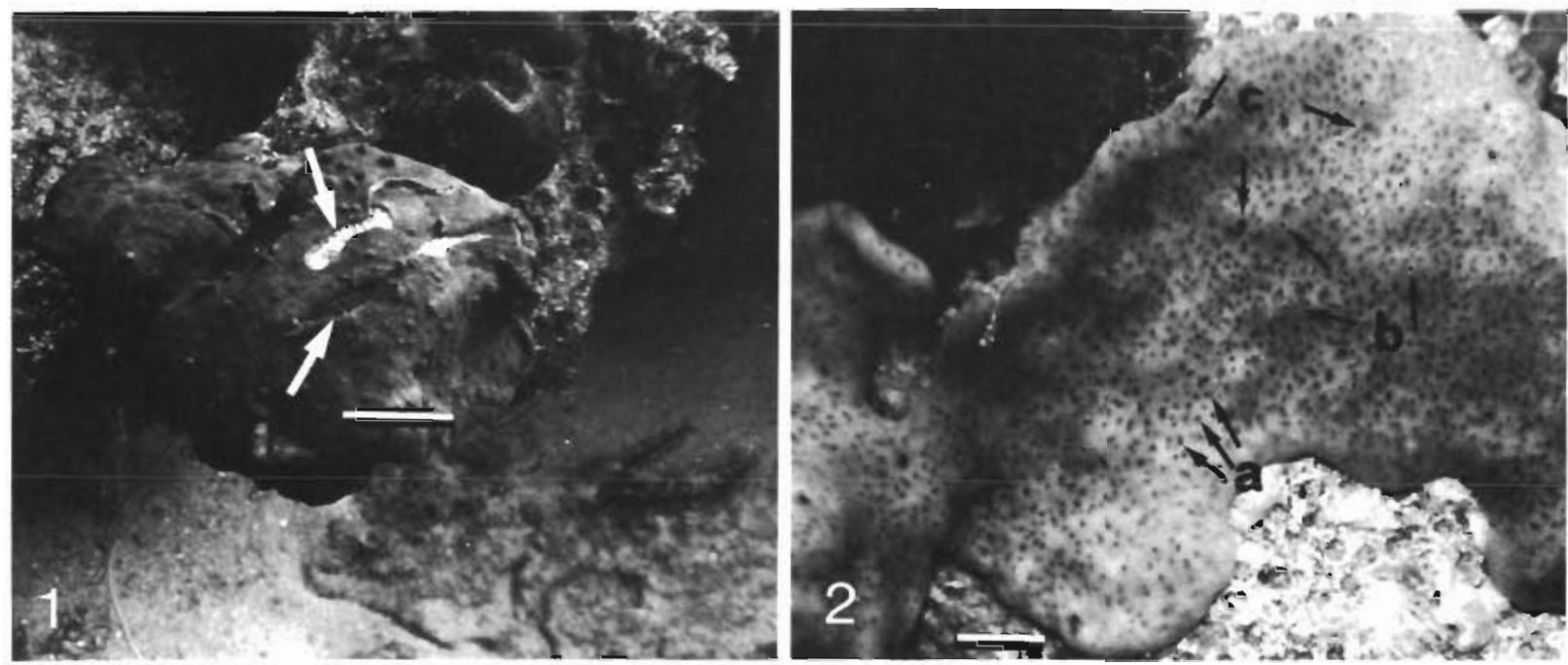

Fig. 1. Trididemnum solidum. 1. Colonies at depth of $20 \mathrm{~m}$ on Carmabi reef. Note margins of colonins expanding over living coral surface (Siderastrea siderea, lower arrow). Retraction of ascidian test uncovers white dead coral surface (upper arrow). Scale bar $10 \mathrm{~cm}$. 2: Colony surface photographed at 11 a.m. Arrows indicate: a, small zooids; b, common cloacal apertures; $c_{\text {, emerging }}$ larvae. Scale bar $1 \mathrm{~cm}$

marked 38 colonies with surface floats to be fortnightly monitored, but due to frequent division and fusion of the colonies (Bak et al., 1981) it became more meaningful to record the number of reproductive clones in the population than the number of reproductive colonies.

We calculated the mean water temperature at $20 \mathrm{~m}$ depth (recorded at Carmabi Reef) and the mean number of sun hours (recorded $7 \mathrm{~km}$ from study reefs, Campbell-Stokes sunshine recorder) for each fortnight preceding a survey of the reproductive colonies. The mean maximum diameter (mean of maximum diameter and maximum diameter perpendicular on first measurement) of all colonies was measured regularly (11 surveys) during the 9 mo interval. in the trap at 50 min time intervals from $09.30 \mathrm{~h}$ to $14.00 \mathrm{~h}$ (all hatching occurs within this interval). Larvae were counted once at $5 \mathrm{~min}$ intervals during releasing time. We used 2 , fairly large $130 \mathrm{~cm}$ mean diameter), reproductive colonies in these experiments. The colonies were located $100 \mathrm{~m}$ from each other at a depth of $18 \mathrm{~m}$ at Carmabi Reef.

\section{Free-Swimming Period and Settlement Behaviour}

We transported colonies, containing fully developed larvae, in seawater containers from the reef to the laboratory. Such colonies continuously released larvae. To determine the length of time between libera- 
tion from the parent colony and settlement, 80 larvae were transferred immediately upon release with a pipette to 80 glass beakers $(180 \mathrm{ml})$. The time interval between release and settlement of each larva was recorded. We considered a larva settled when small water currents from the pipette did not carry the larva from the substratum

To determine the influence of attached larvae on free-swimming larvae we added 63 larvae to 63 beakers containing a settled larva. Ambient light intensities

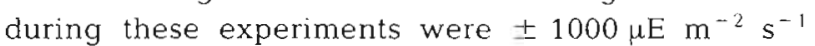
(400-700 nm, LI-185 quantummeter, LI-COR Ltd).

Behaviour after hatching was studied in Plexiglas tanks $(80 \times 25 \times 25 \mathrm{~cm})$, horizontally divided in imaginary compartments with decreasing light intensities through the compartments. We introduced 198 larvae at random to a range of $1275-0.7 \mu \mathrm{E} \mathrm{m}^{-2} \mathrm{~s}^{-1}$. Depths corresponding to these light levels were obtained from van den Hoek et al. (1978). We observed the pattern of free-swimming behaviour and recorded the location of settled larvae $4 \mathrm{~h}$ after the start of the experiment. Experimental temperatures were approximately $28^{\circ} \mathrm{C}$.

\section{Substratum Preference}

We exposed free-swimming larvae to a choice of substrata in 10 aerated aquaria (rounded edges, $16 \times 12 \times 12 \mathrm{~cm}$ ). Substrata included: glass, Coral skeleton I (Acropora cervicornis fragments collected at beach, $8 \mathrm{~cm}$ long, $1.5 \mathrm{~cm}$ diameter, cleaned and dried); Coral skeleton II (same type collected at reef, natural micro-organisms); the living corals Agaricia agaricites (Linnaeus), Montastrea annularis (Ellis and Solander) and Eusmilia fastigiata (Pallas). These scleractinians are the most common as neighbour to Trididemnum solidum on the reef (Bak et al., 1981). The surface of each substratum was measured and expressed as percentage of total available surface area. The number of larvae used in the experiments, as well as the number released per aquarium, was dependant on the supply of larvae (number released by the freshly collected parent colonies). Experimental temperature ranged from $26^{\circ}$ to $27^{\circ} \mathrm{C}$. Settlement was recorded $4 \mathrm{~h}$ after release of the larvae.

\section{Growth and Survival of Recruits in Situ}

We placed 3 different panels (roughened Plexiglas $30 \times 30 \mathrm{~cm}$, roughened PVC $20 \times 30 \mathrm{~cm}$, asbestos 40 $\times 40 \mathrm{~cm}$ ) below and next to a colony $(20 \mathrm{~m}$ depth) which produced $>100$ larvae $\mathrm{d}^{-1}$. The panels were marked with a $2 \times 2 \mathrm{~cm}$ grid to facilitate localization of recruits. The Plexiglas panel became heavily overgrown with filamentous algae and these were periodically removed. We inspected the panels every 2-3 weeks from August 17 to December 4, 1978 recording diameter and location of recruits. We distinguished 2 stages in the recruits: a brown stage - newly settled larvae coloured by concentrated algae in the spat of the tadpole, and a light purplish stage - with visible incurrent ostia and colour of larger colonies.

\section{RESULTS}

\section{Reproductive Period}

We observed reproductive colonies and fully developed tadpole larvae continuously throughout the year. The percentage of all clones being reproductive during the 9 mo of quantitative observations is shown in Fig. 2. The ascidian population maintains the larval production but clones do stop for intervals of 1-2 mo, although 4 clones remained continuously active. Mean numbers of mature larvae per reproductive clone varied between 8 and 44 . Of course, absolute numbers produced were much higher and ranged over 200 larvae clone $e^{-1}$ (or colony ${ }^{-1}$ ) $\mathrm{d}^{-1}$.

There was an interesting relation between the number of larvae produced and the parameters water temperature and number of sun hours (Fig. 3). Number of larvae and mean temperature of the preceding fortnight were significantly related (Kendall rank correlation, $\mathrm{p}<0.005$ ) until January 1979 for the sample from Carmabi Reef. At this point in time water temperature
Fig. 2. Trididemnum solidum. Percentage of clones (n varies from 28 to 34 ) releasing tadpole larvae in two reef areas at the south west coast of Curaçao

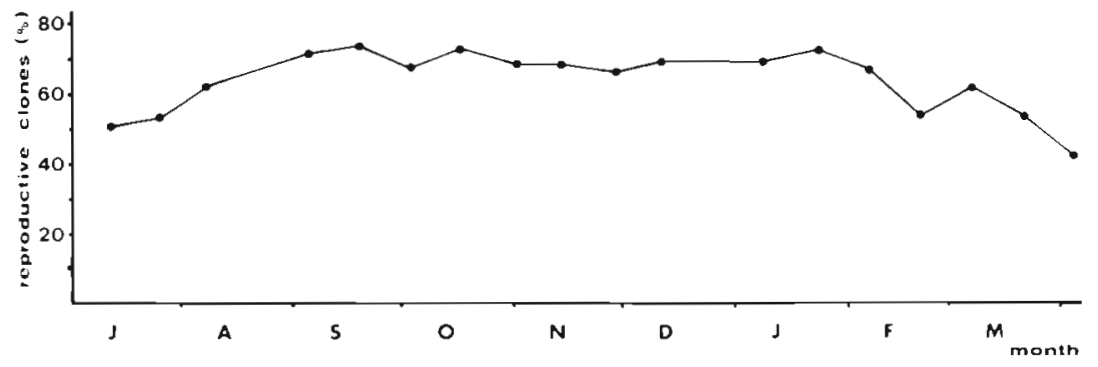




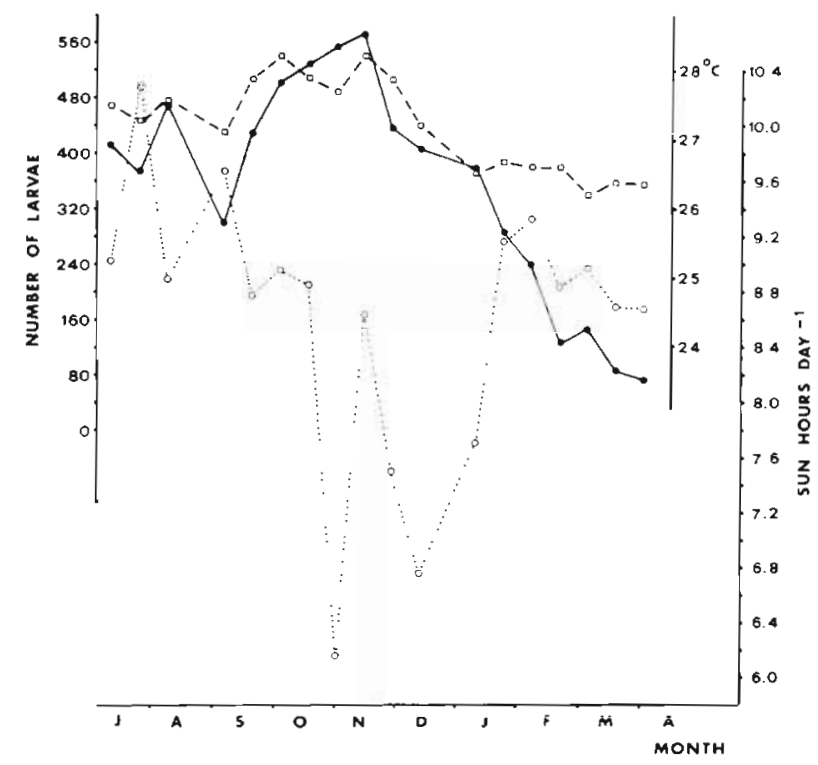

Fig. 3. Trididemnum solidum. Number of larvae (closed circles) present in the Carmabi Reef sample at data point, mean temperature (squares), mean number of sun hours $d^{-1}$ of the preceding fortnight (open circles)

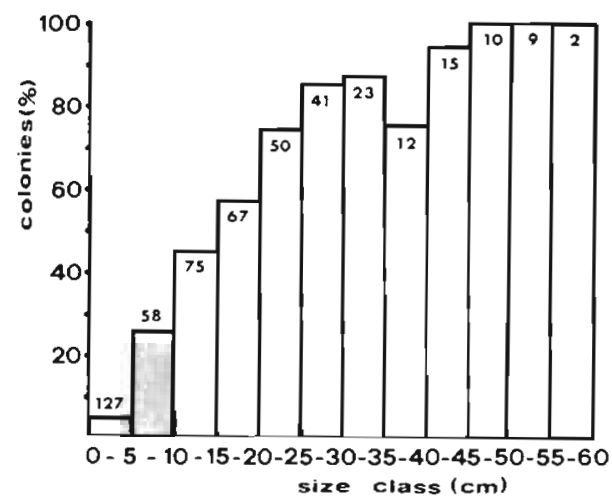

Fig. 4. Trididemnum solidum. Percentage of reproductive colonies per size class (mean diameter). Shaded part of bar represents reproductive colonies originating from larger colonies through colony division. Sample size $n$ indicated in bars

dropped below $27^{\circ} \mathrm{C}$. Temperature records were not available from Vaersen Bay and there was no significant correlation between the number of larvae in Vaersen Bay and the Carmabi Reef temperature records. From January onward there was a significant positive relation (Kendall rank correlation, $\mathrm{p}<0.05$ ) between number of larvae and sun hours (mean of preceding fortnight). This correlation existed for our whole sample.

The relation between the production of larvae and colony size is shown in Fig. 4. Colonies with a mean diameter $\geqslant 45 \mathrm{~cm}$ were all releasing larvae. Reproductive colonies with a mean diameter $\leqslant 10 \mathrm{~cm}$ originate through division from larger reproductive colonies (see Bak et al., 1981; their Fig. 3). Such colonies ceased to produce larvae within 6 wh after division.

\section{Releasing Time and Number of Released Larvae}

The releasing period is very definite and extends from 10.15 to $14.00 \mathrm{~h}$. Initially there is a rapid increase in the number of larvae released, to reach a maximum between 11.15 and $12.15 \mathrm{~h}$. followed by a slow decrease. This pattern is shown in Fig. 5 for 2 colonies sampled during a total of $7 \mathrm{~d}$ at 50 min intervals. An additional set of data collected at 5 min intervals is superimposed on the 50 min data.

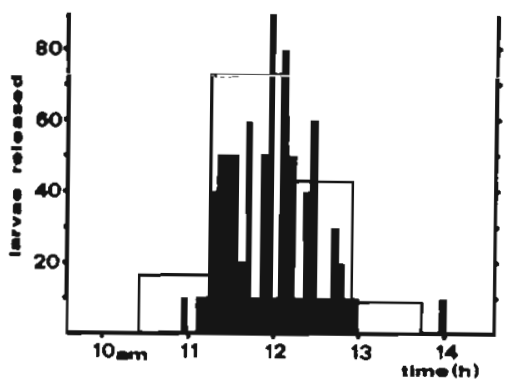

Fig. 5. Trididemnum solidum. Mean number of larvae released on the reef per time unit. White broad bars represent mean of 7 observations (2 colonies); counts at 50 min intervals. Black narrow bars represent an additional observation employing counts at 5 min intervals $(10 \times)$

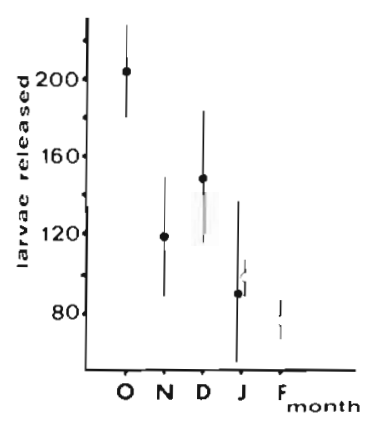

Fig. 6. Trididemnum solidum. Fluctuations in number of larvae released per day (time span Oct. 1978-Feb. 1979). Closed circles: Colony 1, $22 \mathrm{~d}$ of observation. Open circles: Colony 2. $9 \mathrm{~d}$ of observation. Bars indicate SD

Although the number of larvae released per day did not show large variation, the number varies per time of the year and per colony One colony sampled for larvae on $22 \mathrm{~d}$ released 224 to 27 larvae $\mathrm{d}^{-1}$. The number of larvae released decreased significantly through time (anova, $F_{4}=9.33, p<0.001$. Fig 6). The same phenomenon is obvious in Fig. 3; it coincides with a decrease in the number of reproductive clones (Fig. 2). 


\section{Free-Swimming Period and Settlement Behaviour}

The sojourn of Trididemnum solidum larvae into the water column is of very limited duration (Fig. 7). The shortest free-swimming periods observed were less than 2 min ( 3 ind.) and the majority of the larvae settled within 15 min. Of our total sample of 143 larvae, 136 settled within $3 \mathrm{~h}$, the remainder did not attach to the substratum and were found motionless at the bottom. Larvae with free-swimming periods extended to 5 and $7 \mathrm{~h}$ were unable to settle.

The presence of recruits did stimulate settlement in free-swimming tadpoles (Fig. 7). The swimming time of larvae added to beakers containing recruits was significantly shortened ( $t$ test, $\mathrm{p}<0.02$ ).

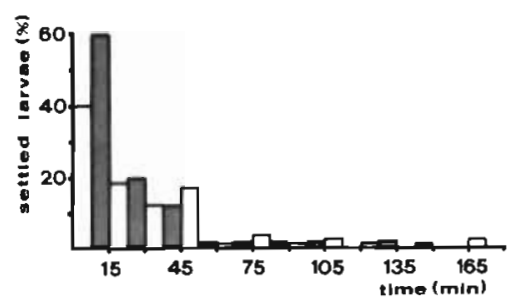

Fig. 7 Trididemnum solidum. Length of free-swimming period in larvae. Larvae added to beakers without (white bars, $n=75$ ) and with settled larvae (shaded bars, $n=61$ )

When larvae were released in tanks with a light gradient they swam approximately horizontally to the compartment with the highest light intensity. Subsequently they surfaced and kept swimming along the wall of this compartment. Swimming activity was frequently interrupted by instants of passivity during which the motionless larvae sank towards the bottom. After a short time (15-30 s) they started swimming to the most illuminated part of the surface again. During the next stage the larvae moved to the darker parts of the tank, where they started to display the small scale searching behaviour typical of the time prior to settlement.

A few times (6 occasions) we observed the freeswimming behaviour on the reef. Immediately upon release the larvae started swimming vigorously up in the water column, their swimming effort alternating with short periods of inactivity. When they arrived at 1 to $5 \mathrm{~m}$ above the parent colony (in 1 to $5 \mathrm{~min}$ ) these 2 modes of behaviour, swimming upwards and motionless sinking, are alternated with short bursts of swimming in disregard of their previous vertical orientation. We have seen them at this stage to swim industriously in circles, sinking passively a few decimeters to pick up their original orientation towards the water surface. In the next phase they became definitely photonegative and moved actively towards dark substrata or objects, again interrupted by motionless periods. We never observed searching behaviour on the substratum and subsequent settling in the field because the larvae were lost in crevices between the corals.

Table 1. Trididemnum solidum. Larval settlement at different light intensitıes (comparable depths taken from van den Hoek et al., 1978), expressed as percentage of settlers. Total experimental larvae $n=198$. Total number of settlers $n=145$

\begin{tabular}{|ccc|}
\hline $\begin{array}{c}\text { Light intensity } \\
\left(\mu \mathrm{E} \mathrm{m}^{2} \mathrm{~s}^{-1}\right)\end{array}$ & $\begin{array}{c}\text { Depth } \\
(\mathrm{m})\end{array}$ & $\begin{array}{c}\text { Settled larvae } \\
(\%)\end{array}$ \\
\hline 1250 & 2 & 1 \\
81 & 26 & 19 \\
38 & 34 & 26 \\
17 & $>40$ & 50 \\
1.3 & $>40$ & 3 \\
\hline
\end{tabular}

Settlement of larvae was obviously influenced by ambient radiation (Table 1 ). In the control experiment larvae settled evenly at both halves of the tank. The percentage non settlers was $35 \%$ at experimental and $26 \%$ at control conditions.

\section{Substratum Preference}

The Trididemnum larvae selected strongly for a certain type of substratum (Table 2). Coral skeleton was the favourable site for attachment, skeleton covered with micro organisms being preferred. It appeared that the larvae do not settle on living coral tissues.

Table 2.Trididemnum solidum. Substratum preference of larvae expressed as percentage settled larvae per unit surface area. A: Smooth/rough surface $(\mathrm{n}=35$, not settled $34 \%)$. B: Rough surface without (coral skeleton [)/with micro organisms (Coral skeleton II) ( $n=63$, not settled $22 \%$ ). C: Living coral/Coral skeleton II $(n=118$, not settled $17 \%)$. Preference significant in each case $\left(\alpha^{2}, p<0.001\right)$

\begin{tabular}{|lccc|}
\hline Substratum & $\begin{array}{c}\text { A } \\
\text { \% settled } \\
\text { larvae }\end{array}$ & $\begin{array}{c}\text { B } \\
\text { \% settled } \\
\text { larvae }\end{array}$ & $\begin{array}{c}\mathrm{C} \\
\text { \% settled } \\
\text { larvae }\end{array}$ \\
\hline Glass & 9 & 5 & 11 \\
Coral skeleton I & 91 & 19 & 89 \\
Coral skeleton II & & 76 & 0 \\
Living coral & & & \\
\hline
\end{tabular}

\section{Growth and Survival of Recruits in Situ}

During our 4 mo of observation, 29 larvae settled on the panels. After attachment to the substratum the larvae entered an inactive period of 3 to $4 \mathrm{wk}$. In this 
interval the larvae metamorphose. The colour of the larvae at this stage is brown and, although there was no increase in size the shape of the larvae became more irregular. Following this interval, the recruits started budding (asexual proliferation of zooids) and grew out to small colonies. Thirteen settlers had disappeared before reaching this state. The remaining small colonies grew to sizes of 3 to $4 \mathrm{~mm}$ in 30 to $60 \mathrm{~d}$ after settlement, but all had disappeared at the end of the observation period.

We found a few (4) aggregations of freshly settled larvae on natural reef substrata in the immediate vicinity of large Trididemnum colonies. Checking on presence/absence of these recruits through time showed all these larvae to disappear during the first stage.

\section{DISCUSSION}

In Curaçao, Trididemnum solidum populations are sexually reproductive throughout the year. Continuous breeding was recorded in other tropical ascidians (Goodbody, 1961; Morgan, 1978), but seasonal breeding also occurs (Millar, 1974). Among the ascidian species found by Millar to display a periodicity in the breeding cycle in Panama (Atlantic side) is $T$. solidum. Millar suggested temperature and/or turbidity (light levels) to synchronize the breeding activity. Both these environmental factors parameters appear to have controlled the amount of larvae released per unit time in our study. Another reason to expect the influence of different light levels to modify internal conditions in the ascidian test is their association with symbiotic algae (Sybesma et al., 1981). We found a change in the relative importance of temperature and light levels when temperature drops below $27^{\circ} \mathrm{C}$ (Fig. 3). Importance of this particular temperature in the physiology of $T$. solidum is also suggested by the significantly higher proportion of large breeding colonies in the population, as well as a significant increase in disintegration phenomena at temperatures $>27^{\circ} \mathrm{C}$ (Bak et al, 1981). The data from Curaçao and Panamá show that $T$. solidum is capable of breeding throughout the year, but breeding may be limited by adverse conditions.

We have no indications that the tough test of Trididemnum solidum, heavily impregnated with spicules, act as barrier in the release of larvae. The larvae are released daily and at suitable temperatures new tadpoles are probably formed within 10-20 h. Embryonic development (to completion of tadpole larvae) lasts approximately $10 \mathrm{~h}$ at $27^{\circ} \mathrm{C}$ in other ascidians (Berrill, 1935). We only rarely found larvae retained in the test after $14.00 \mathrm{~h}$. Release can be interrupted by precocious metamorphosis (Berrill, 1931;
Millar, 1952), but our impression is that these larvae were dead and hence unfit to partake actively in the releasing process.

The releasing period was very definite $(10.15 \mathrm{~h}$ to $14.00 \mathrm{~h}$ ), but the ecological significance is unclear. It is well known, however, that ascidians are physiologically stimulated, possibly through activation of a hormone (Huus, 1941), by the alternation of certain periods of darkness and light (Watanabe and Lambert, 1973; West and Lambert, 1976).

Trididemnum solidum colonies start to produce larvae when they attain a critical size of $11-15 \mathrm{~cm}$. They are not compelled to cover all available space for colony expansion before sexually maturing as in some compound ascidians (Yamaguchi, 1975). Absent also is the dramatic drop in growth rate (colony expansion) once the colonies commence sexual reproduction (Morgan, 1978). T solidum may have relatively easy access to the additional energy required for reproduction and growth because of its association with symbiotic algae.

Length of the free-swimming period of ascidians under laboratory conditions varies from a few min to several d according to species (Millar, 1971). The majority of the Trididemnum solidum larvae attached within 15 min. Grave and Nicoll (1939) suggested attachment to be delayed under experimental, compared with field conditions. A higher activity in the field would increase the amount of metabolic byproduct essential for activation of metamorphosis. Crisp and Ghobasky (1971) proved in experiments that intermittent light, as opposed to continuous light reduced the length of the free-swimming period. Our field observations appear to confirm our experimental results. Although we always lost the larvae as soon as they entered the crevices between the corals, the time they spent in the water column over the reef never exceeded $10 \mathrm{~min}$.

The behaviour of the larvae under experimental conditions, swimming towards the brightest compartment with subsequent movement to the surface, indicates a strong positive phototaxis with a weaker geonegative component. The observations in the field do not discriminate between phototaxis and geotaxis in the first phase but later the larvae moved clearly towards dark abjects in disregard of the direction of gravity.

Presence of a settled larva in an experimental beaker stimulated larval attachment of larvae. We observed aggregations of recruits in the field, but did no experiments to investigate possible gregariousness (sensu Scheltema, 1974) of Trididemnum larvae. Gregarious settlement has been described in other ascidian species (Young and Braithwaite 1980). An advantage of possible associative settlement in $T$. solidum can be related to the phenomenon of fusion (Bak et al., 1981). 
Fusion of genetically identical small. colonies produces larger colonies in relatively short periods, a functional quality in a species which starts to reproduce at a specific colony size.

Kott (1974) has argued that there exists an evolutionary trend in viviparous ascidians to shorten the duration of the swimming period. This would limit dispersal over wide areas and result in dense local popula. tions with a high probability of sexual interaction From this point of view Trididemnum solidum must be considered advanced among the didemnid ascidians, e.g. the free-swimming periods for $T$. cereum (Giard), Polysyncraton (Didemnum) amethysteum (Van Name), Didemnum gelatinosum (Milne Edwards) and Diplosoma listerianum gelatinosum (Milne Edwards) are 1, 1-2, 2 and 5-6 h, respectively (Berrill 1935).

The limits set by the length of the pelagic phase and a current pattern is clear in the distribution around Curaçao (Bak et al., 1981). A continuous (daily) supply of larvae with very limited time in the water column will be very effective in colonizing available substrata in the vicinity of the colonies. New space for settling in the reef habitat is not created by dramatic and unique events, but occurs relatively frequently on a small scale (Bak and Luckhurst, 1980). The reproductive strategy of Trididemnum solidum is highly successful in such a habitat.

The free-swimming behaviour of larvae of Trididemnum solidum strongly resembles the common pattern in ascidian larvae (see Millar 1971). As most pelagic larvae they initially exhibit a strong positive and weak geonegative behaviour (Thorson 1964). This accomodates the dispersal of larvae while the final photonegative phase leads the larvae to the substratum. The results (Table 1) show that there is a strong tendency to select regions of very low light intensities. Crisp and Ghobashy (1971) observed the same phenomenon in Diplosoma listerianum. However, $T$. solidum larvae avoided the darkest part of the experimental tank and preferred light intensities of $5-25 \mu \mathrm{E} \mathrm{m}{ }^{-2} \mathrm{~s}^{-1}$ for settlement. At midday, when the larvae are active on the reef, these light intensities occur deeper than $40 \mathrm{~m}$ at the open reef bottom. $T$. solidum ranges over the reef profile from depths of 1.5 to $34 \mathrm{~m}$ (Bak et al., 1981) and it appears that the larvae settle in this zone selecting spots of lower than ambient light level. This results in their settlement in holes and crevices between the corals, keeping away from the exposed sunfaces. That the frequency of settling decreases at the lowest radiation levels is not surprising for an organism containing symbiotic algae. The darkest micro-habitats are avoided because light is essential for survival of the larvae.

Little is known regarding the choice of substrata by ascidian larvae or indeed if much choice is exercised
(Millar, 1971). The site selection capacity in Trididemnum solidum appeared to be well developed. The larvae avoid environments with too high or too low light intensities, they avoid settling on living coral and prefer coarse substratum with a natural micro-flora. This pattern of settlement clearly affects the distribution and abundance of colonies on the reef. Larger colonies are very common between the protruding living parts of the scleractinian coral Eusmilia fastigiata (Pallas), Montastrea annularis (Ellis and Solander) and Agaricia agaricites (Linnaeus) (Bak et al., 1981). The characteristics of crevices between the living parts of these corals correspond very well with the microhabitat preference of the larvae

Mortality was very high among the settled larvae we monitored in situ. The recruits are very inconspicuous. Our observations showed larvae not to be considered palatable by corals or fishes, but the recruits we monitored were exposed to grazing organisms, such as the sea urchin Diadema antillarum Philippi and parrotfishes (Scaridae), as well as to spatial competition with filamentous algae. The experiments on settling behaviour indicate that the exposed position of these recruits is not typical for most settling larvae. Both grazing pressure and spatial competition with algae is reduced in microhabitats between the corals, possibly resulting in higher survival rates.

In conclusion, the reproductive strategy of Trididemnum solidum consists of stable components. Larvae are released throughout the year to colonize the continuously renewed resource space. In order to accomplish this the larvae employ a well developed site selection apparatus. Population densities are maintained by an extremely short free-swimming life and possible gregarious settlement, resulting in increased reproductive success.

Acknowledgements. We want to express our gratitude to Oscar Frans, Frank Isabella and Aubrey Tiel for assistance in the field and to $C$. Th. Cardoze for technical help. The Meteorological Service Curacio provided the sun hour data. We thank. Dr R. H. Millar (Scotland) for redding the manuscript. The third author was supported by a grant from the Beyerinck-Popping Fund, Holland.

\section{LITERATURE CITED}

Alldredge, A. L., King, J. M. (1977). Abundance of demersal reef zooplankton. Mar. Biol. 41: 317-333

Bak, R. P. M., Luckhurst, B. E. (1980). Constancy and change in coral reef habitats along depth gradients at Curaçao. Oecologia 47: 145-155

Bak, R. P. M., Sybesma, J., van Duyl, F. C. (1981). The ecology of the tropical compound ascidian Trididemnum solidum. II. Abundance, growth and survival. Mar. Ecol. Prog. Ser. 6: $43-52$

Berrill, N. J. (1931). Studies in tunicate development. Part II. 
Abbreviation of development in the Molgulidae. Phil Trans. R. Soc. (Ser B) 219:281-346

Berrill, N. J. (1935). Studies in tunicate development, Part III Differential retardation and acceleration. Phil. Trans. R. Soc. (Ser B) 225: 255-326

Crisp, D. J., Ghobashy, A. F. A. A. (1971). Responses of the larvae of Diplosoma listerianum to light and gravity. In Crisp, D. J. (ed.) Fourth European Marme Biological Symposium. University Press, Cambridge, pp. 443-465

Goodbody, 1. (1961). Continuous breeding in three species of tropical ascidians. Proc. zool. Soc. Lond. 136: 403-409

Grave, C., Nicoll, P. A. (1939). Studies of larval life and metamorphosis in Ascidia nigra and species of Polyandrocarpa. Pap. Tortugas Lab. 32: 3-46

Herdman. W. A. (1886). Report on the Tunicata collected during the voyage of $\mathrm{H} . \mathrm{M}$. S. 'Challenger' during the years 1873-1876. It. Ascidiae compositae. Zool. Challenger Exped. 14: 1-432

Hoek, C. van den, Breeman, A. M., Bak, R. P. M., van Buurt, G. (1978). The distribution of algae, corals and gorgonians in relation to depth, light attenuation, water movement and grazing pressure in the fuinging coral reet of Curafao, Netherlands Antilles. Aquat. Bot. 5: 1-46

Huus, 1. (1941). Effects of physical factors on the spawning in ascidians. Temperature limits for spawning. Avh. norske VidenskAkad. Oslo 1941 (8) 1-13

Kott, P. (1974). The evolution and distribution of Australian tropical Ascidiacea. In: Proceedings of Second International Coral Reef Symposium, Vol. 1 Great Barrier Reef Committee, Brisbane, pp. 405-423

Millar, R. H. (1952). The annual growth and reproductive cycle in four Ascidians. J. mar. biol. Ass. U.K. 311: 41.-61

Millar, R. H. (1962). Some ascidians from the Caribbean. Stud. Faund Curaçao, 13: 61-77

Millar, R. H. (1971). The biology of ascidians. Adv. mar. Biol. 9: $1-100$

Millar, R. H. (1974). A note on the breeding season of three ascidians on coral reefs at Galeta in the Caribbean sea. Mar Biol. 28: 127-129

Morgan, T. O. (1977). Growth rate, age and sexual maturity, longevity, and seasonality in three West Indian colonict ascidians. M. Sc. thesis, Unuversity Puerto Rico, Mayagüez Puerto Rico

Name, W G van (1902). The Ascidians of the Bermuda Islands. Trans. Conn. Acad. Sci. 11. 325-412

Scheltema, R. S. (1974). Bjological interactions determining larval settlement of marine invertebrates. Thalassia jugosl. 10: 263-296

Sybesma, J., Bak, R. P. M. (1979). The distribution of Trididemnum solidum (van Name), an algae containing compound ascidian along the coast of Curaçao (N.A.). Proc. Ass. Isl. Mar. Lab. Carib. Santo Domingo 14:6

Sybesma, J., van Duyl, F. C., Bak, R. P. M. (1981). The ecology of the tropical compound ascidian Trididemnum soljdum. III. Symbiotic association with unicellular algae. Mar Ecol. Prog. Ser. 6: 53-59

Thorson, G. (1964). Light as an ecological factor in the dispersal and settlement of larvae of marine bottom invertebrates Ophelia 1: 167-208

Watanabe, H., Lambert, C. C. (1973). Larva release in response to light by the compound Ascidians Distaplla occidentalis and Metancrocaspa taylori. Biol. Bull. mar biol. Lab., Woods Hole 144: 556-566

West, A. B., Lambert, C. C. (1976). Control of spawning in the tunicate Styela plicata by variations in a natural light regime. J. exp. Zool. 195: 263-270

Yamaguchi, M. (1975). Growth and reproductive cycles in the marıne fouling ascidians Ciona intestinalis, Styela plicata, Botrylloides violaceus and Leptoclinum mitsukurii at Aburatsubo - Moroiso Inlet (Central Japan) Mar Biol. 29 : 253-259

Young, C. M., Braithwaite, L. F. (1980). Larval behaviour and post settling morphology in the ascidian, Chelyosoma productum Stimpson. J. exp. mar Biol. Ecol. 42: 157-169 